\title{
Highly Ordered Boron Nitride Nanotube Arrays with Controllable Texture from Ammonia Borane by Template-Aided Vapor-Phase Pyrolysis
}

\author{
Yuting Wang, Yasunori Yamamoto, Hajime Kiyono, and Shiro Shimada \\ Graduate School of Engineering, Hokkaido University, Sapporo 060-8628, Japan \\ Correspondence should be addressed to Yuting Wang, ytwang@eng.hokudai.ac.jp
}

Received 14 July 2008; Accepted 16 November 2008

Recommended by Nobuhiro Matsushita

An efficient approach for the preparation of good-quality boron nitride nanotubes (BNNTs) is developed. BNNTs with specific texture were prepared from ammonia borane $\left(\mathrm{BH}_{3} \mathrm{NH}_{3}\right)$ by vapor-phase pyrolysis with the aid of a template in two independent temperature-controlled furnaces. Two kinds of BNNTs, 200-300 nm wide $\times 60 \mu \mathrm{m}$ long and $70-80 \mathrm{~nm}$ wide $\times 40 \mu \mathrm{m}$ long, were produced after removal of the templates. The as-produced BNNTs were heated at different temperatures in the range of 1300$1700^{\circ} \mathrm{C}$ in $\mathrm{NH}_{3}$. FT-IR and XPS results confirmed the formation of $\mathrm{BN}$ from $\mathrm{BH}_{3} \mathrm{NH}_{3}$. Ordered arrays of BNNTs without cracks on the surface were seen using microstructural observations. The diameter and length of the BNNTs are controlled using templates with different pore sizes and thickness. The wall thickness of the nanotubes was increased by increasing the number of deposition cycles. The crystallinity of the BNNTs was improved by heating at a high temperature $\left(1700^{\circ} \mathrm{C}\right)$ in $\mathrm{NH}_{3}$.

Copyright ( $) 2008$ Yuting Wang et al. This is an open access article distributed under the Creative Commons Attribution License, which permits unrestricted use, distribution, and reproduction in any medium, provided the original work is properly cited.

\section{INTRODUCTION}

Recently, one-dimensional (1D) nanostructured materials, such as nanotubes, nanowires, and nanobelts, have attracted much attention on account of their novel chemical and physical properties. Boron nitride nanotubes (BNNTs), which are structurally similar to carbon nanotubes (CNTs), display several outstanding properties for technological applications, including gas absorption, field emission measurement, and thermal conductivity [1-7]. BNNTs are considered to be more suitable than carbon nanotubes for several applications since BNNTs demonstrate high oxidation resistance up to $800^{\circ} \mathrm{C}$ in air, in contrast to CNTs that are readily oxidized at around $400^{\circ} \mathrm{C}$. Furthermore, the electronic properties of BNNTs, independent of the diameter and chirality, allow for novel applications in nanoelectronics and optoelectronics.

There have been many studies on CNTs, whereas there have been relatively fewer reports on the preparation and applications of BNNTs, probably because the synthesis of BNNTs with high quality as well as the control of texture (i.e., diameter, length, and inner space) is more difficult and expensive compared to CNTs. Thus far, BNNTs have been synthesized using arc discharge [8], substitution reaction with CNTs [9], ball milling of BN powder [10], thermal annealing of a mixed powder of boron and hexagonal boron nitride (h-BN) [11], and chemical vapor deposition (CVD) using a mixture of $\mathrm{B}$ and $\mathrm{MgO}$ vapor [5]. However, almost all of these methods require complicated and expensive apparatus or severe preparation conditions. In particular, all methods have difficulty with the control of the texture of nanotubes and the assembly of individual nanotubes into highly ordered arrays. To the best of our knowledge, no previous approach to the synthesis of BNNTs that can fulfill all these requirements has been reported.

To produce ordered arrays of nanotubes with controlled diameter and length, template-aided synthesis has been suggestedas one of the major approaches. A porous alumina anodic (PAA) membrane has been used as a suitable template for the synthesis of 1D nanostructures because of its tunable pore dimensions, narrow pore size distribution, and good mechanical and thermal stability [12]. Although PAA membranes are commercially available, it is of interest to use homemade ones with different textures (e.g., uniform length and pore diameter) to produce different kinds of nanotubes. 


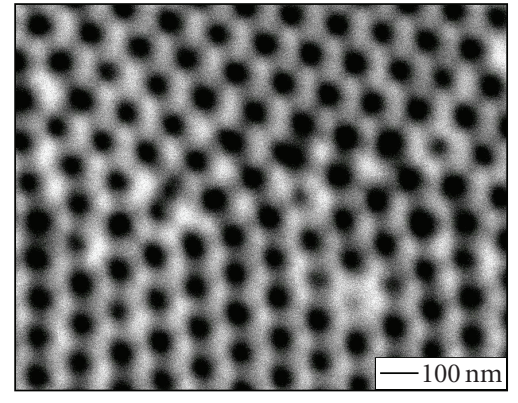

FIGURE 1: SEM image of the homemade PAA membrane.

Several starting materials have been reported for the synthesis of BN materials, including borazine, polyvinylpentaborane, or dibromoboranedimethyl sulphide, which is known to be a good precursor to form BN upon ammonia thermolysis. In our previous study, BNNTs with highly ordered arrays were successfully prepared by wetting the PAA template with borazine $\left(\mathrm{B}_{3} \mathrm{~N}_{3} \mathrm{H}_{6}\right)$ [13]. However, both ends of the BNNTs were sealed by a thin $\mathrm{BN}$ film formed by the deposition of the liquid polymer precursor on the template surface, causing difficulties with further adjusting functionality and applications of the BNNTs. In addition, it was also difficult to control the wall thickness or inner diameter of the nanotubes by the wetting approach.

In order to overcome these problems in our previous study, it was recommended to use a gaseous organometallic precursor of $\mathrm{BN}$ for the formation of BNNTs in the PAA template. In this respect, ammonia borane $\left(\mathrm{BH}_{3} \mathrm{NH}_{3}\right)$ is considered to be a suitable precursor for the preparation of BNNTs through vapor-phase pyrolysis since $\mathrm{BH}_{3} \mathrm{NH}_{3}$ is a stable crystalline solid with less toxicity without $\mathrm{C}$ and $\mathrm{O}$ and can be easily transformed into the gas phase by moderate temperature heating $[14,15]$. In addition, no catalyst is needed to synthesize $\mathrm{BN}$ using $\mathrm{BH}_{3} \mathrm{NH}_{3}$. This study reports the successful preparation of BNNTs with high quality in highly ordered arrays and controllable texture from $\mathrm{BH}_{3} \mathrm{NH}_{3}$ using template-aided vapor-phase pyrolysis.

\section{EXPERIMENTAL DETAILS}

\subsection{Materials}

Ammonia borane was synthesized from sodium borohydride $\left(\mathrm{NaBH}_{4}\right)$ and ammonium sulfamate $\left(\mathrm{NH}_{4} \mathrm{NH}_{2} \mathrm{SO}_{3}\right)$, as described by Suenram and Thorne [16]. The composition of this product using ${ }^{1} \mathrm{H}-\mathrm{NMR}$ was found to be $97 \mathrm{wt} \%$ $\mathrm{BH}_{3} \mathrm{NH}_{3}$ and $\approx 3 \mathrm{wt} \%\left(\mathrm{BH}_{2} \mathrm{NH}_{2}\right)_{x(x<3)}$.

Two types of PAA templates were used in this study. One was a commercially available alumina anodic membrane $60 \mu \mathrm{m}$ thick with a nominal pore diameter of $100 \mathrm{~nm}$ (Anodisc 13, Whatman Ltd.). The other was a homemade membrane, about $40 \mu \mathrm{m}$ thick with pore diameters $\leq 80 \mathrm{~nm}$, which was formed based on the method reported by Thompson (Figure 1) [12]. Before being used, the PAA templates were cleaned in an ultrasonic bath using distilled water, ethanol, and acetone, and successively dried at $50^{\circ} \mathrm{C}$ in air.

\subsection{Preparation of BNNTs}

The experimental apparatus used is shown in Figure 2(a). Two independent temperature-controlled furnaces (I and II) were set in a glove box filled with $\mathrm{N}_{2}$. One-side-closed silica glass tube functioned as the reaction chamber in the furnaces. An amount of $0.3 \mathrm{~g}$ of $\mathrm{BH}_{3} \mathrm{NH}_{3}$ was placed in the glass tube positioned in furnace (II), while the alumina template was attached to the outlet of the silica glass tube in furnace (I). However, furnace (I) was first heated to $550^{\circ} \mathrm{C}$, and then furnace (II) was heated from room temperature to $250^{\circ} \mathrm{C}$ at a heating rate of $10^{\circ} \mathrm{C} \mathrm{min}^{-1}$, and maintained for 1 hour at this temperature. After furnace (II) was cooled down naturally, furnace (I) was kept at $550^{\circ} \mathrm{C}$ for another 24 hours. Consequently, amorphous BNNTs were formed in the PAA template. To obtain BNNTs with different wall thicknesses, the deposition step was repeated using the same template. The template filled with the BNNTs was then moved out from the glove box and heated in a horizontal tube furnace using a two-cycle heat treatment program, as shown in Figure 2(b). Also, BN heated at high temperature $\left(>1300^{\circ} \mathrm{C}\right)$ is chemically inert in a strong base solution. Crystallized BN obtained by the 1st cycle heat treatment at $1300^{\circ} \mathrm{C}$ was not dissolved by the $\mathrm{NaOH}$ solution. The template with the BNNTs was then heated to $1300^{\circ} \mathrm{C}$ at a rate of $10^{\circ} \mathrm{C} \mathrm{min}^{-1}$ and then kept for 1 hour in $\mathrm{NH}_{3}$ flowing at $100 \mathrm{~mL} \mathrm{~min}^{-1}$ (1st cycle) and washed with ethanol for 30 minutes in an ultrasonic bath. The template with BNNTs was etched in a $40 \mathrm{wt} \% \mathrm{NaOH}$ solution to dissolve the template. The BNNTs free of alumina were washed several times using dilute water and ethanol, and then successively dried at $100^{\circ} \mathrm{C}$ in air. As shown by the $2 \mathrm{nd}$ cycle of the heat treatment, alumina-free BNNTs were placed in a BN boat and heated from room temperature to $1400^{\circ} \mathrm{C}$ at $10^{\circ} \mathrm{C} \mathrm{min}-1$. They were maintained at this temperature for 1 hour, followed by further heating at 1500,1600 , and $1700^{\circ} \mathrm{C}$ for 1 hour in $\mathrm{NH}_{3}$ gas $\left(100 \mathrm{~mL} \mathrm{~min}^{-1}\right)$.

\subsection{Characterization}

The texture and morphology of the BN nanotubes obtained after heat treatment at the final temperature of 1300, 1500, 1600 , and $1700^{\circ} \mathrm{C}$ were observed using scanning electron microscopy (SEM; JEOL JSM 6500F) and high-resolution transmission electron microscopy (HRTEM; JEM2000) with selected area electron diffraction (SAED) at an accelerating voltage of $200 \mathrm{kV}$ and energy dispersive spectroscopy (EDS). Fourier transform infrared spectroscopy (FT-IR; Thermo Nicolet AVATAR 320) measurements were carried out to determine the formation of $\mathrm{BN}$.

\section{RESULTS AND DISCUSSION}

FT-IR spectra of $\mathrm{BH}_{3} \mathrm{NH}_{3}$ and BNNTs after heating using a two-step heat treatment at $1400 / 1700^{\circ} \mathrm{C}$ in $\mathrm{NH}_{3}$ are shown 


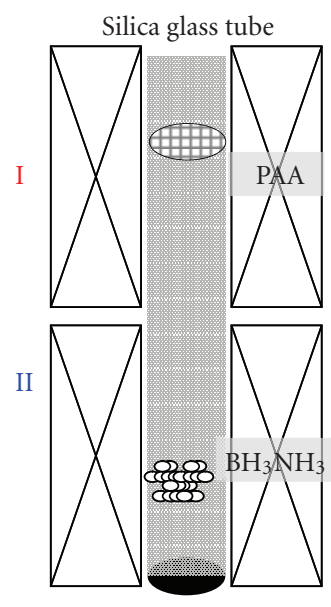

(a)

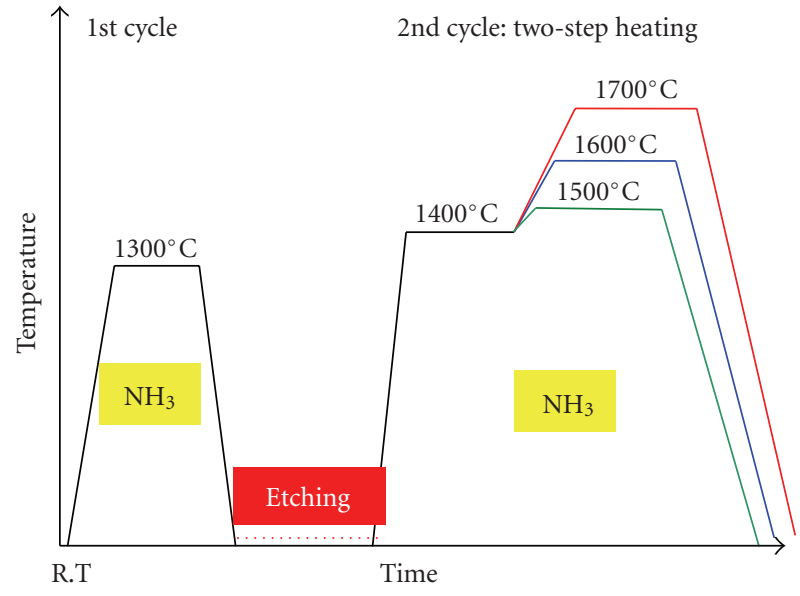

(b)

FIgURE 2: Experimental apparatus (a) and the two-cycle heat treatment program (b) used in the study.

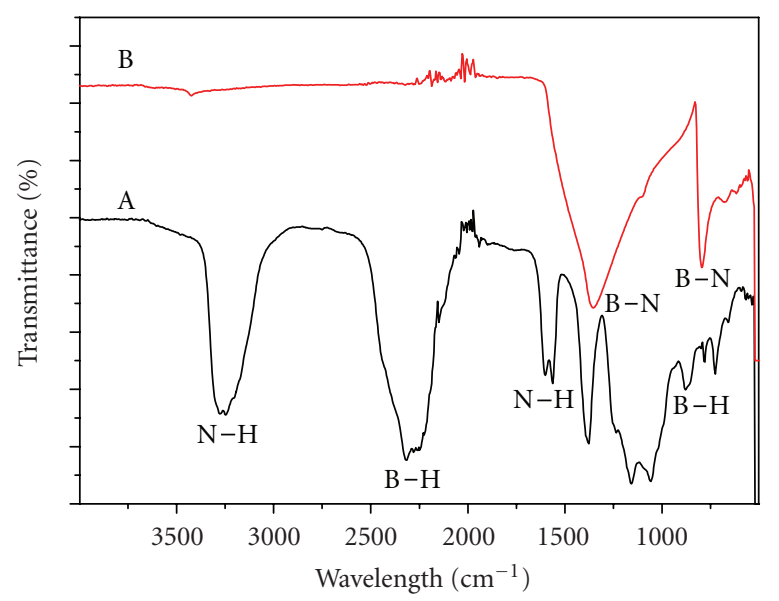

FIgURE 3: FT-IR spectra of $\mathrm{BH}_{3} \mathrm{NH}_{3}$ (A) and BNNTs heated to $1400 / 1700^{\circ} \mathrm{C}$ in $\mathrm{NH}_{3}$ (B).

in Figure 3. Typical peaks due to stretching of $\mathrm{N}-\mathrm{H}$ and $\mathrm{B}-$ $\mathrm{H}$ bonds in $\mathrm{BH}_{3} \mathrm{NH}_{3}$ appear at 3280 and $2320 \mathrm{~cm}^{-1}$, respectively, with the $\mathrm{N}-\mathrm{H}$ deformation at $1560 \mathrm{~cm}^{-1}$ (Figure 3(a)). After the heat treatment at $1400 / 1700^{\circ} \mathrm{C}$, these peaks disappeared because of dehydrogenation with polymerization and condensation [17]. Peaks corresponding to $\mathrm{B}-\mathrm{N}$ stretching were observed at 1380 and $780 \mathrm{~cm}^{-1}$ (Figure 3(b)). On the other hand, XPS spectra of the BNNTs formed at the final temperature of $1700^{\circ} \mathrm{C}$ showed $\mathrm{N}_{1 \mathrm{~s}}$ and $\mathrm{B}_{1 \mathrm{~s}}$ peaks at the binding energy of 397.65 and $190.15 \mathrm{eV}$ [18], respectively. The B:N ratio was given to be about 1:1 from the areas under the peaks. The formation of $\mathrm{BN}$ from $\mathrm{BH}_{3} \mathrm{NH}_{3}$ by pyrolysis was confirmed on the basis of the FT-IR and XPS results. Since neither oxygen nor carbon was seen to exist in $\mathrm{BH}_{3} \mathrm{NH}_{3}$, it is obvious that BNNTs can be prepared without oxygen and carbon impurities.

Figure 4 shows bundles of template-free BNNTs prepared by heating at $1300^{\circ} \mathrm{C}$ (1st cycle). Highly ordered arrays of BNNT bundles can be observed, with the maximum length of the BNNTs reaching $60 \mu \mathrm{m}$ (Figure $4(\mathrm{a})$ ). As seen in Figure 4(b), straight BNNTs were formed with diameters ranging from 200 to $300 \mathrm{~nm}$, corresponding to the pore sizes of the PAA template. Neither cracks nor residual alumina can be seen on the surfaces of the BNNTs. An enlarged image (Figure 4(c)) of the middle part from Figure 4(a) shows broken BNNTs which were probably formed during SEM sample preparation. Figure 4(c) confirms the hollow structure of the BNNTs, as indicated by the arrows. Also, Figure 4(d) shows that BNNTs with open ends were formed without the formation of films on the top surfaces.

Figure 5 shows TEM images of BNNTs produced at $1300^{\circ} \mathrm{C}$ (1st cycle) in $\mathrm{NH}_{3}$. Long, straight, and hollow nanotubes about $200 \mathrm{~nm}$ wide including Y-shaped ones were observed (Figure 5(a)). The Y-shaped nanotube should be inherited from channels of the template. The wall thickness of the BNNT was about $8 \mathrm{~nm}$ (Figure 5(b)). It was found that the wall thickness of the as-prepared BNNTs had a narrow range from 5 to $10 \mathrm{~nm}$. Because of the thin walls, the BNNTs have very large inner diameters ranging from 180 to $280 \mathrm{~nm}$, several tens of times larger than those of BNNTs prepared using other approaches $[5,10,11]$. SAED from the walls of the nanotubes yielded BN (002), (100), and (110) reflections (inset in Figure 5(b)), and the strong arcs of (002) revealed the turbostratic structure of the BNNTs. EDX analysis showed the absence of $\mathrm{Al}$ and $\mathrm{O}$ elements in the BNNT samples. When the BNNTs that were formed at $1300^{\circ} \mathrm{C}$ were directly heated to temperatures higher than $1500^{\circ} \mathrm{C}$, the original morphology of the BNNTs was broken. Therefore, a two-step heat treatment, shown in Figure 2(b), was applied to maintain the morphology of the BNNTs with high crystallinity.

Figure 6 shows high-resolution TEM images of BNNTs obtained by the one-step heat treatment at $1300^{\circ} \mathrm{C}$ and the two-step heat treatment at $1400 / 1500^{\circ} \mathrm{C}, 1400 / 1600^{\circ} \mathrm{C}$, and $1400 / 1700^{\circ} \mathrm{C}$ (2nd cycle). Compared with the BNNTs prepared using the single-step process at $1300^{\circ} \mathrm{C}$ (1st cycle) 


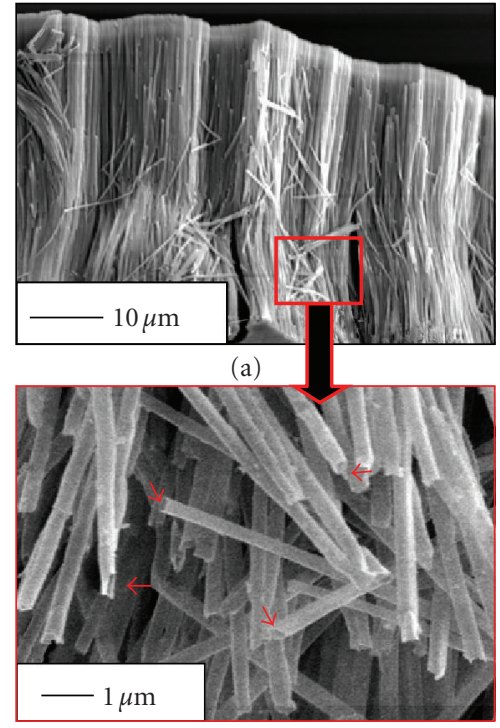

(c)

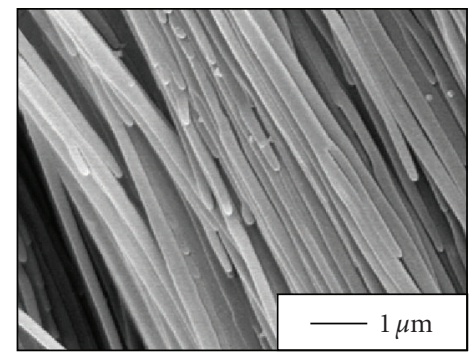

(b)

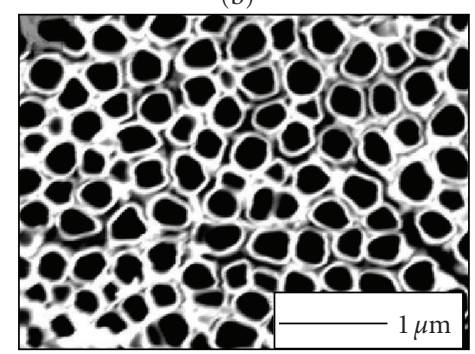

(d)

FIgURE 4: SEM images of highly ordered BNNT arrays obtained at $1300^{\circ} \mathrm{C}$ (1st cycle) after removal of the PAA template. Cross-section of BNNTs ((a) and (b)), fragments of broken BNNTs (c), and top view of the BNNT bundles (d).

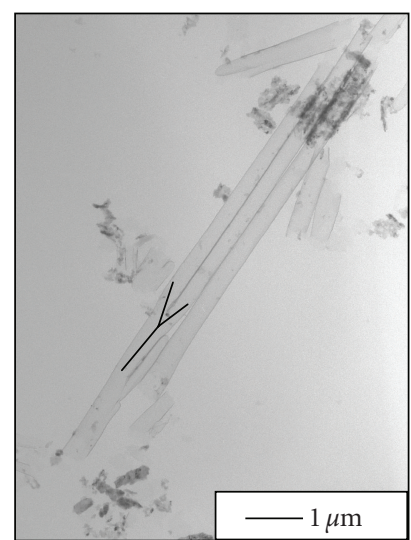

(a)

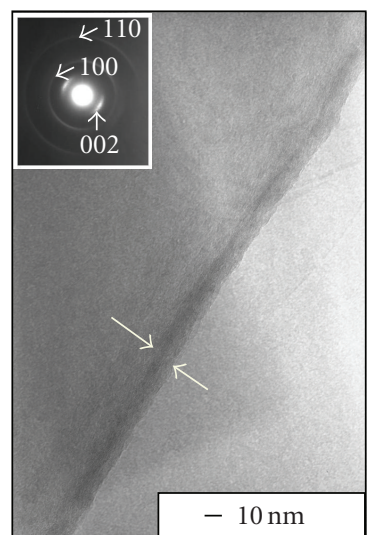

(b)

FIgure 5: TEM images of BNNTs formed at $1300^{\circ} \mathrm{C}$ (1st cycle) in $\mathrm{NH}_{3}((\mathrm{a})$ and (b)); the inset in image (b) shows the ED pattern of the nanotube wall.

(Figure 6(a)), the crystalline planes of the BNNTs obtained by the two-step heat treatment tend to run along the long axis of the nanotubes parallel to the $c$-axis of h-BN (see arrows). The BNNTs treated at $1700^{\circ} \mathrm{C}$ (Figure $6(\mathrm{~d})$ ) show regular spacingsof about $0.34 \mathrm{~nm}$, close to the theoretical value of $0.333 \mathrm{~nm}$ of h-BN (002) (Joint Committee on Powder Diffraction Standards (JCPDS) Card no. 73-2095), which also confirms the formation of h-BN. The order degree of the stacking layers of $\mathrm{BN}$ was gradually increased by heating from 1300 to $1700^{\circ} \mathrm{C}$. The angle of inclination of the crystallites from the long axis of the nanotube decreased gradually from 1300 to $1700^{\circ} \mathrm{C}$. It is to be noted that the BNNTs obtained at $1700^{\circ} \mathrm{C}$ show a well-ordered layer structure similar to the BNNTs deposited on graphite at $1200^{\circ} \mathrm{C}$ from the $\mathrm{B}-\mathrm{N}-\mathrm{O}$ precursor vapor generated at $1700^{\circ} \mathrm{C}$ by the CVD method
[19]. The distribution of plane crystallites in the BNNTs after heat treatment at $1300,1500,1600$, and $1700^{\circ} \mathrm{C}$ is shown in Figure 7(a). The lengths of the crystallites became longer with increasing heat treatment from 1300 to $1700^{\circ} \mathrm{C}$. The average length of the $\mathrm{BN}$ crystallites exponentially increased with temperature (Figure 7(b)). In particular, the mean length of the crystallites grew to $17 \mathrm{~nm}$ when the BNNTs were heated to $1700^{\circ} \mathrm{C}$. It is understood that the crystallinity of the BNNTs can be distinctly improved by heating at high temperatures in $\mathrm{NH}_{3}$.

The BNNTs after heat treatment at $1300-1700^{\circ} \mathrm{C}$ were washed in distilled water and ethanol to remove contamination on the surface. When BNNTs heated at $1300^{\circ} \mathrm{C}(1 \mathrm{st}$ cycle) were inadequately dried and moved into the vacuum chamber of the SEM or TEM, some of the BNNTs became 


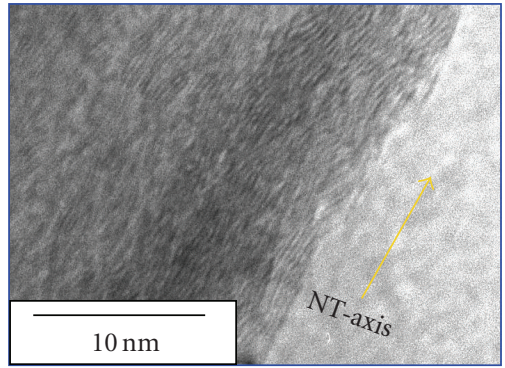

(a)

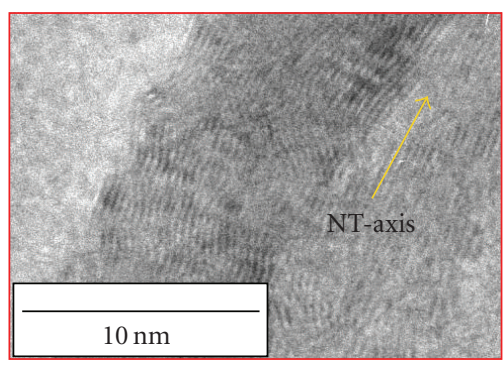

(c)

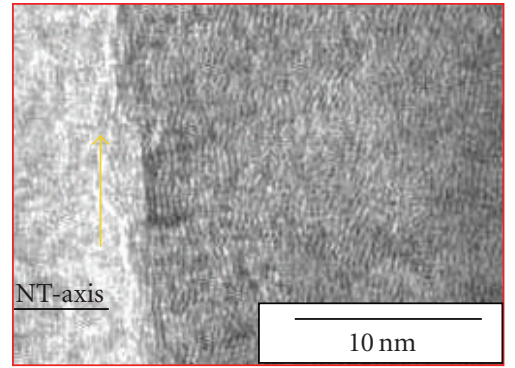

(b)

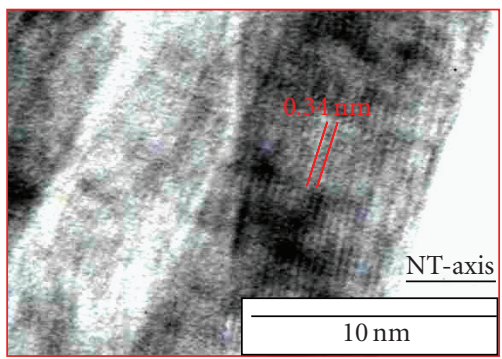

(d)

FIgURE 6: HRTEM images of the BN layers after heating to 1300 (a), 1500 (b), 1600 (c), and $1700^{\circ} \mathrm{C}$ (d).

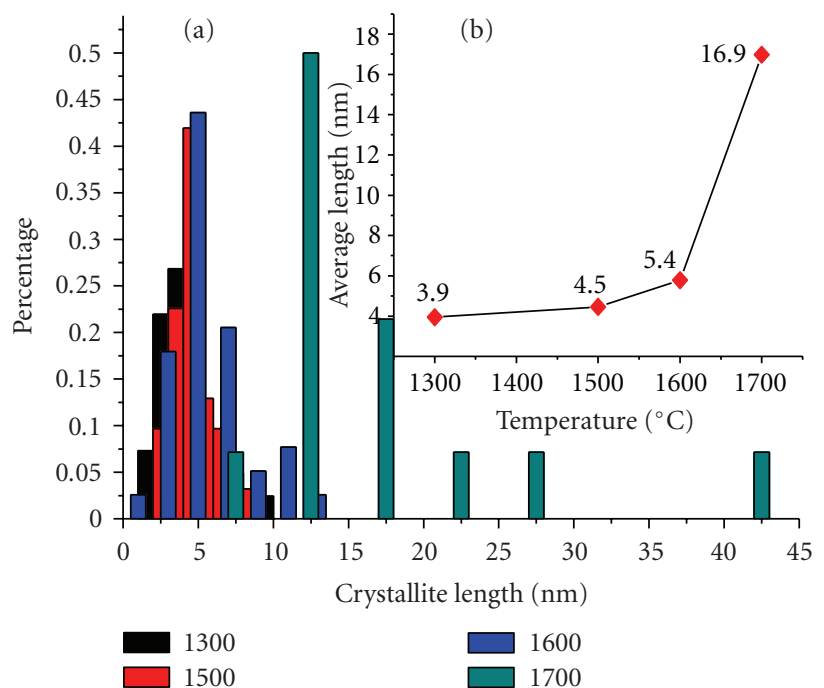

FIGURE 7: Length distribution of the BN crystallites (a) and the relationship between average length of the $\mathrm{BN}$ crystallites and temperature (b) in the BNNTs after heating to a final temperature of $1300,1500,1600$, and $1700^{\circ} \mathrm{C}$ in $\mathrm{NH}_{3}$.

flat and were bent, curling the bundles (Figure $8(\mathrm{a})$ ). It is of interest to observe a flat, twisted BNNT without cracks (Figure $8(\mathrm{~b})$ ).

In order to increase the thickness of the walls of the BNNTs, a template was reversed after the first deposition and the $\mathrm{B}-\mathrm{N}-\mathrm{H}$ containing polymer was subsequently deposited again in such a manner as mentioned in experimental procedure. As a result, we obtained the wall of BNNTs doubly thick. The wall thickness was increased from 9 to
$20 \mathrm{~nm}$ by the double deposition (Figure 9), indicating that the wall thickness can be controlled by the number of deposition cycles. When the homemade template with a pore diameter $\leq 80 \mathrm{~nm}$ and a thickness of $40 \mu \mathrm{m}$ was used, BNNTs with corresponding sizes (i.e., diameter $\leq 80 \mathrm{~nm}$ and length $\approx 40 \mu \mathrm{m}$ ) were successfully prepared after heating at $1300^{\circ} \mathrm{C}$ (1st cycle) (Figure 10(a)). The wall thickness in this case was less than $10 \mathrm{~nm}$ (Figure 10(b)), comparable to that of the BNNTs fabricated using the commercial template, suggesting that the wall thickness is determined by the amount of starting $\mathrm{BH}_{3} \mathrm{NH}_{3}$ material, independent of the template size. In addition, flat and bent BNNTs surrounding the bundles also were observed (see arrows).

The overall reaction for the formation of BNNTs from $\mathrm{BH}_{3} \mathrm{NH}_{3}$ can be expressed as follows $[14,16,20]$ :

$$
\mathrm{BH}_{3} \mathrm{NH}_{3} \longrightarrow \mathrm{BN}+3 \mathrm{H}_{2} \text {. }
$$

A mechanism for the formation of BNNTs is schematically shown in Figure 11. The formation of BNNTs from $\mathrm{BH}_{3} \mathrm{NH}_{3}$ consists of two steps. First, $\mathrm{BH}_{3} \mathrm{NH}_{3}$ is heated to $250^{\circ} \mathrm{C}$ in furnace (II) and it decomposes to gaseous $\mathrm{H}_{2}, \mathrm{BH}_{2} \mathrm{NH}_{2}$, and $\mathrm{B}_{3} \mathrm{~N}_{3} \mathrm{H}_{6}$ [20]. These gaseous precursors $\mathrm{BH}_{2} \mathrm{NH}_{2}$ and $\mathrm{B}_{3} \mathrm{~N}_{3} \mathrm{H}_{6}$ are carried upward with $\mathrm{H}_{2}$. Second, when these gases go through the narrow channels of the template at $550^{\circ} \mathrm{C}$ in furnace (I), pyrolysis of $\mathrm{BH}_{2} \mathrm{NH}_{2}$ and $\mathrm{B}_{3} \mathrm{~N}_{3} \mathrm{H}_{6}$ readily occurs, resulting in deposition of solid, amorphous BN films at the surfaces of the walls of the channels. As the reaction proceeds, BN films without cracks on the surface are uniformly thickened to several nanometers. After heat treatment $\left(\geq 1300^{\circ} \mathrm{C}\right)$, with subsequent removal of the PAA template, highly ordered BNNTs arrays with a specific texture are produced. 


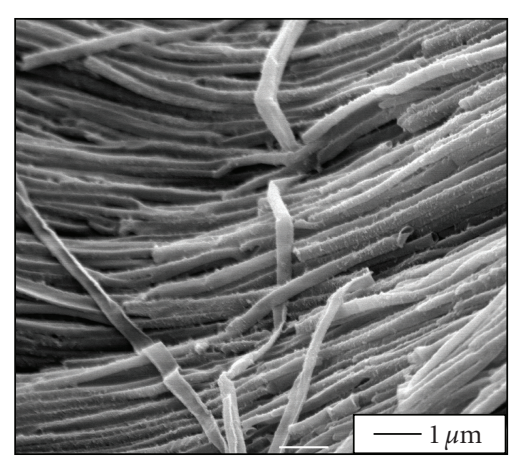

(a)

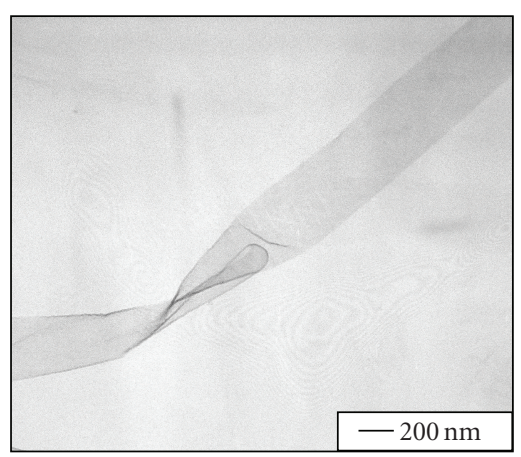

(b)

FIGURE 8: (a) SEM image of flat BNNT containing curled or twisted ones obtained at $1300^{\circ} \mathrm{C}$ (1st cycle). (b) TEM image of a flat BNNT without cracks.

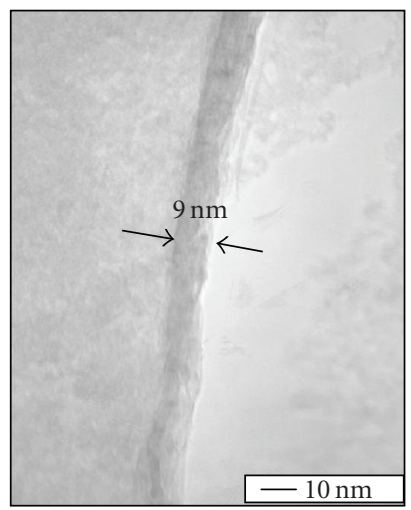

(a)

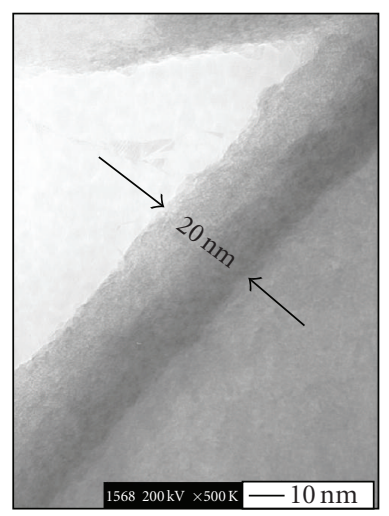

(b)
FIGURE 9: TEM images of BNNTs by depositing BN once (a) and twice (b).

\section{CONCLUSIONS}

We report a simple and efficient route to the production of highly ordered BNNT arrays with controllable texture from $\mathrm{BH}_{3} \mathrm{NH}_{3}$. Two kinds of BNNTs, 200-300 nm wide $\times 60 \mu \mathrm{m}$ long and $70-80 \mathrm{~nm}$ wide $\times 40 \mu \mathrm{m}$ long, were obtained with a wall thickness less than $10 \mathrm{~nm}$. It was found that the BNNT

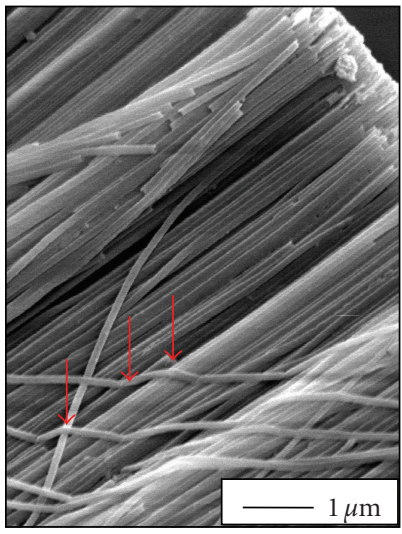

(a)

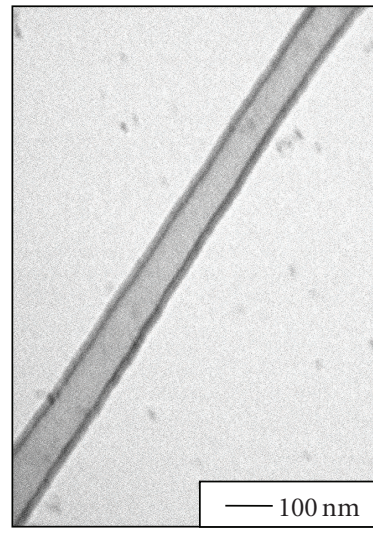

(b)
Figure 10: SEM (a) and TEM (b) images of BNNTs prepared using the homemade PAA template with a pore diameter of about $80 \mathrm{~nm}$.

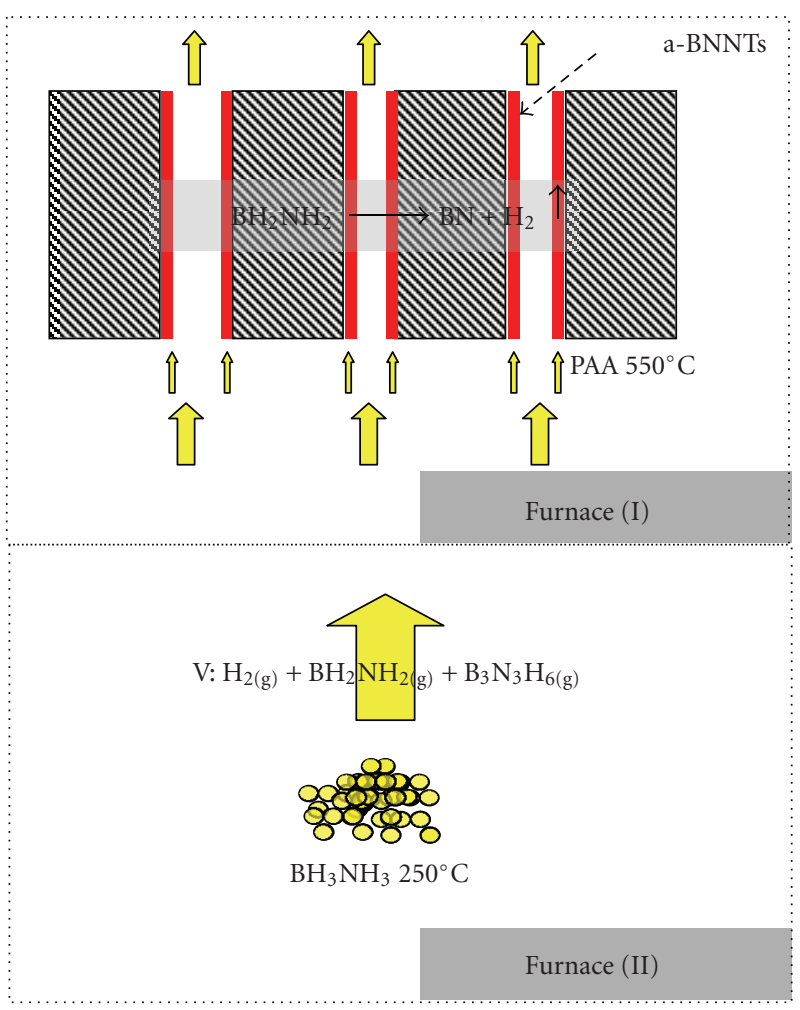

FIgURE 11: A mechanism for the formation of BNNTs from $\mathrm{BH}_{3} \mathrm{NH}_{3}$ with the aid of a template.

wall thickness could be increased by repeating the deposition. The crystallinity of the BNNTs improved by heat treatment at $\geq 1300^{\circ} \mathrm{C}$ in $\mathrm{NH}_{3}$, and $\mathrm{BN}$ crystallites grew to $17-44 \mathrm{~nm}$ at $1700^{\circ} \mathrm{C}$. A mechanism for the formation of BNNTs from $\mathrm{BH}_{3} \mathrm{NH}_{3}$ was proposed including several steps involving the pyrolysis of $\mathrm{BH}_{3} \mathrm{NH}_{3}$, deposition in the PAA templates, and crystallization of $\mathrm{BN}$. 


\section{ACKNOWLEDGMENTS}

This work was supported by Global COE program (Project no. B01: catalysis as the basis for innovation in Materials Science) from the Ministry of Education, Culture, Sports, Science and technology, Japan). We appreciate Ms. JUNKO Umeda and Mr. YUKI Nagasawa for their help to synthesize $\mathrm{BH}_{3} \mathrm{NH}_{3}$.

\section{REFERENCES}

[1] N. G. Chopra, R. J. Luyken, K. Cherrey, et al., "Boron nitride nanotubes," Science, vol. 269, no. 5226, pp. 966-967, 1995.

[2] R. Ma, Y. Bando, H. Zhu, T. Sato, C. Xu, and D. Wu, "Hydrogen uptake in boron nitride nanotubes at room temperature," Journal of the American Chemical Society, vol. 124, no. 26, pp. 7672-7673, 2002.

[3] Y.-C. Zhu, Y. Bando, D.-F. Xue, et al., "New boron nitride whiskers: showing strong ultraviolet and visible light luminescence," The Journal of Physical Chemistry B, vol. 108, no. 20, pp. 6193-6196, 2004.

[4] C. Zhi, Y. Bando, C. Tang, and D. Golberg, " $\mathrm{SnO}_{2}$ nanoparticle-functionalized boron nitride nanotubes," The Journal of Physical Chemistry B, vol. 110, no. 17, pp. 85488550, 2006.

[5] C. Tang, Y. Bando, X. Ding, S. Qi, and D. Golberg, "Catalyzed collapse and enhanced hydrogen storage of BN nanotubes," Journal of the American Chemical Society, vol. 124, no. 49, pp. 14550-14551, 2002.

[6] Z. Zhou, J. Zhao, Z. Chen, et al., "Comparative study of hydrogen adsorption on carbon and BN nanotubes," The Journal of Physical Chemistry B, vol. 110, no. 27, pp. 1336313369, 2006.

[7] X. Chen, X. P. Gao, H. Zhang, et al., "Preparation and electrochemical hydrogen storage of boron nitride nanotubes," The Journal of Physical Chemistry B, vol. 109, no. 23, pp. 1152511529, 2005.

[8] A. Loiseau, F. Willaime, N. Demoncy, G. Hug, and H. Pascard, "Boron nitride nanotubes with reduced numbers of layers synthesized by arc discharge," Physical Review Letters, vol. 76, no. 25 , pp. 4737-4740, 1996.

[9] W. Han, Y. Bando, K. Kurashima, and T. Sato, "Synthesis of boron nitride nanotubes from carbon nanotubes by a substitution reaction," Applied Physics Letters, vol. 73, no. 21, pp. 3085-3087, 1998.

[10] J. Yu, Y. Chen, R. Wuhrer, Z. Liu, and S. P. Ringer, "In situ formation of BN nanotubes during nitriding reactions," Chemistry of Materials, vol. 17, no. 20, pp. 5172-5176, 2005.

[11] M. Terauchi, M. Tanaka, K. Suzuki, A. Ogino, and K. Kimura, "Production of zigzag-type BN nanotubes and BN cones by thermal annealing," Chemical Physics Letters, vol. 324, no. 5-6, pp. 359-364, 2000.

[12] G. E. Thompson, "Porous anodic alumina: fabrication, characterization and applications," Thin Solid Films, vol. 297, no. 1-2, pp. 192-201, 1997.

[13] Y. Wang, S. Shimada, Y. Yamamoto, and N. Miyaura, "Preparation of h-BN nano-tubes, -bamboos, and -fibers from borazine oligomer with alumina porous template," Materials Research Bulletin, vol. 43, no. 2, pp. 251-256, 2008.

[14] F. Baitalow, J. Baumann, G. Wolf, K. Jaenicke-Rößler, and G. Leitner, "Thermal decomposition of B-N-H compounds investigated by using combined thermoanalytical methods," Thermochimica Acta, vol. 391, no. 1-2, pp. 159-168, 2002.
[15] D.-P. Kim, K.-T. Moon, J.-G. Kho, J. Economy, C. Gervais, and F. Babonneau, "Synthesis and characterization of poly(aminoborane) as a new boron nitride precursor," Polymers for Advanced Technologies, vol. 10, no. 12, pp. 702$712,1999$.

[16] R. D. Suenram and L. R. Thorne, "Microwave spectrum and dipole moment of $\mathrm{BH}_{3} \mathrm{NH}_{3}$," Chemical Physics Letters, vol. 78, no. 1, pp. 157-160, 1981.

[17] D.-P. Kim, C. G. Cofer, and J. Economy, "Fabrication and properties of ceramic composites with a boron nitride matrix," Journal of the American Ceramic Society, vol. 78, no. 6, pp. 1546-1552, 1995.

[18] A. Goriachko, Y. He, M. Knapp, et al., "Self-assembly of a hexagonal boron nitride nanomesh on $\mathrm{Ru}(0001)$," Langmuir, vol. 23, no. 6, pp. 2928-2931, 2007.

[19] R. Ma, Y. Bando, and T. Sato, "Controlled synthesis of BN nanotubes, nanobamboos, and nanocables," Advanced Materials, vol. 14, no. 5, pp. 366-368, 2002.

[20] M. T. Nguyen, V. S. Nguyen, M. H. Matus, G. Gopakumar, and D. A. Dixon, "Molecular mechanism for $\mathrm{H}_{2}$ release from $\mathrm{BH}_{3} \mathrm{NH}_{3}$, including the catalytic role of the lewis acid $\mathrm{BH}_{3}$," The Journal of Physical Chemistry A, vol. 111, no. 4, pp. 679690, 2007. 

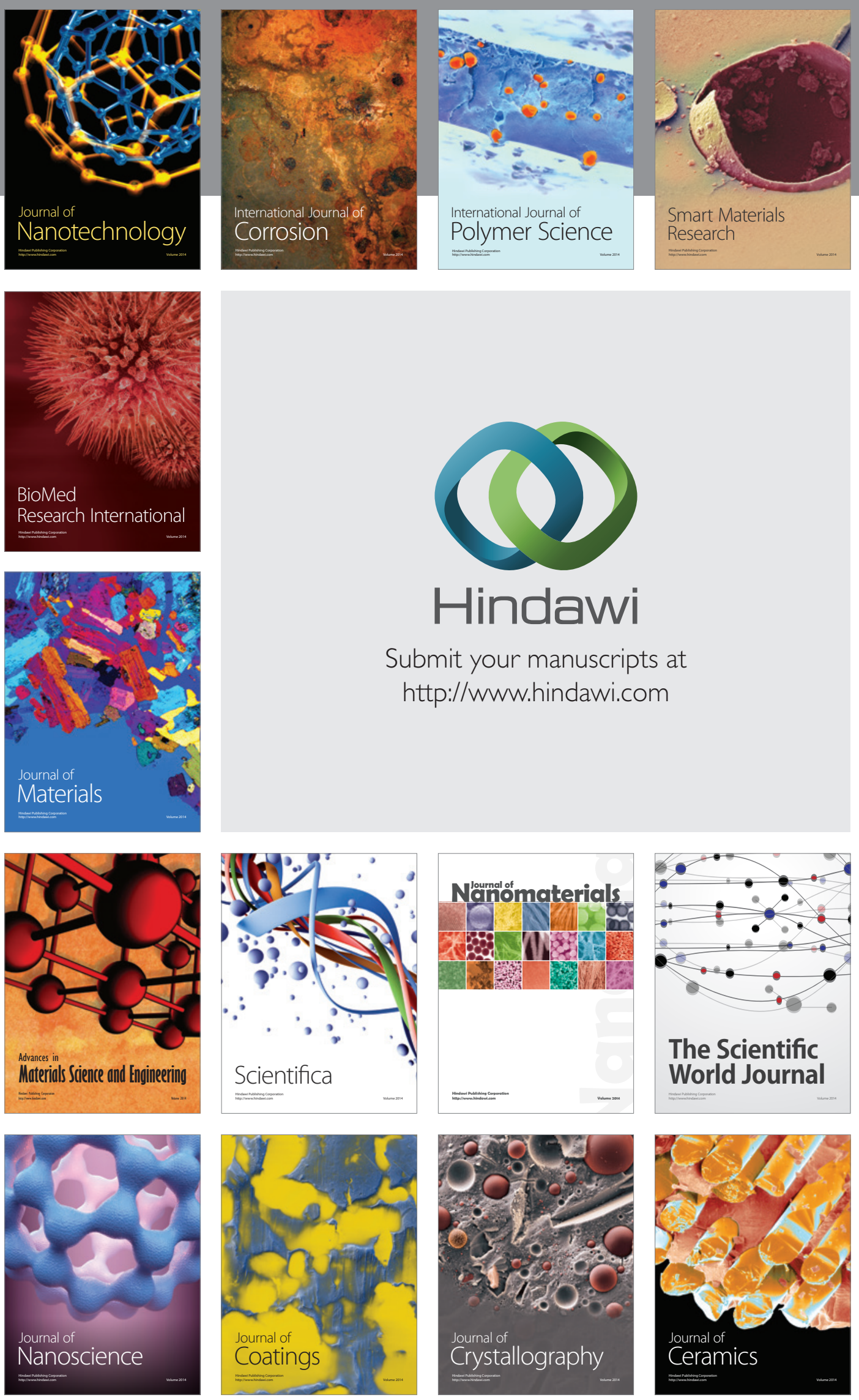

The Scientific World Journal

Submit your manuscripts at

http://www.hindawi.com

\section{World Journal}

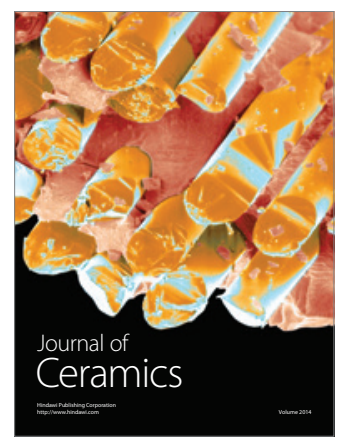

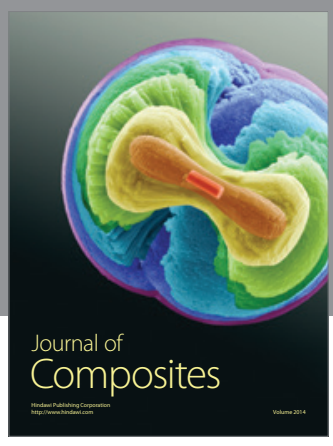
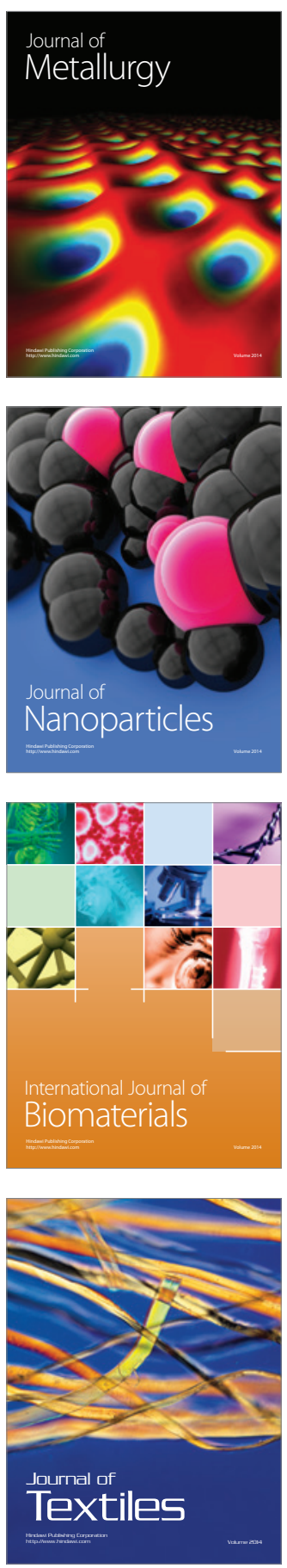